\title{
The effect of personality dimensions on work addiction
}

\author{
Elaheh Sadat Babalhavaeji ${ }^{a}$, Reza Taghvaei ${ }^{b^{*}}$ and Hossein Soleimani ${ }^{b}$
}

${ }^{a}$ MA in Marketing, Department of Marketing, Malayer Branch, Islamic Azad University, Malayer, Iran ${ }^{b}$ Department of Marketing, Malayer Branch, Islamic Azad University, Malayer, Iran

\begin{tabular}{|c|c|}
\hline C H R O N I C L E & A B S T R A C T \\
\hline $\begin{array}{l}\text { Article history: } \\
\text { Received January 5, } 2016 \\
\text { Received in revised format } \\
\text { August 2, } 2016 \\
\text { Accepted August 23, } 2016 \\
\text { Available online } \\
\text { August 23, 2016 } \\
\text { Keywords: } \\
\text { Incompatibility } \\
\text { Extraversion } \\
\text { Altruism } \\
\text { Flexibility } \\
\text { Responsibility and } \\
\text { conscientiousness } \\
\text { Work addiction }\end{array}$ & $\begin{array}{l}\text { The purpose of this study was to investigate the relationship between personality dimensions of } \\
\text { employees and work addiction in Management and Planning Organization of Hamedan. This } \\
\text { study was descriptive-correlation and it was also an applied research in terms of its nature. The } \\
\text { statistical population included all employees in Management and Planning Organization in } \\
\text { Hamedan who worked in } 2016 \text { and their total number was } 74 \text { subjects. In this study, the } \\
\text { statistical sample of employees was estimated up to } 62 \text { individuals using Morgan and Krejcie } \\
\text { tables with simple random method. The measuring tool for personality dimensions was NEO } \\
50 \text {-item short form questionnaire and one for work addiction was Spence and Robbins's } 20- \\
\text { item questionnaire. The results of Pearson correlation and regression analysis showed that all } \\
\text { personality dimensions of employees had a significant relationship with work addiction which } \\
\text { among them, extraversion, flexibility and accountability dimensions had a negative correlation } \\
\text { with work addiction. Also, altruism and flexibility dimensions can predict work addiction, } \\
\text { respectively. }\end{array}$ \\
\hline
\end{tabular}

\section{Introduction}

Among various traits, personality id something which can help people better understand themselves and others; that, an aspect of human life which allows us to predict how a person will behave in a given situation. Personality structure has been developed according to different patterns. Five-factor personality model is considered as one of the most valid and famous personality models with theoretical, experimental and research supports. These factors include: extraversion, adjustment, conscientiousness, emotional stability, openness to experience (Goldberg, 2001). So, the owners of each of the personality aspects behave in particular ways and they have also specific expectations. They have unique abilities and behavioral skills and different needs and specific needs, expectations, motivations and objectives. On the other hand, organizations satisfy specific needs and expectations in terms of their current objectives, tasks and activities. Therefore, different work environments are appropriate for each various personality types (Narimani \& Khanbabazadeh, 2007). So in meanwhile, 
the lack of attention to the relationship between personality and occupational and organizational characteristics causes some problems for the employees (Carver \& Scheirer, 2013).

One of these problems is work addiction among employees; work addiction phenomenon causes some problems for individuals and negligence of their families. Studies have shown that when personality of a person is not consistent with the work environment, organizational conditions, job requirements and competitive conditions of his/her organizational environment, it causes the person to work continuously for organization and thus devote much time to organizational activities whether during the presence in the organization or outside of it, so that the possibility of physical and psychological harm is very high for such people addicted to work (Ahmadi et al., 2010). Work addiction means an uncontrollable need or coercion and inevitability to work and it involves two main elements that include: very intense work and intense innate desire to work (McMillan et al., 2003). In other words, the minds of individuals addicted to work are always involved in matters related to work (Oates, 1971). In this regard, the researches by Gholipour et al. (2010), Ahmadi et al. (2010), Nargesian et al (2012), Pour et al. (2013), Mohkamkar Damghani (2013), Mahmoudian (2014), Scottl et al. (2007), Hamermesh and Slemrod (2008), Piotrowski and Vodanovich (2008), Golzari et al. (2014) reported that problem of work addiction may have a psychological aspect and personality plays an important role in this context. Those who suffer from personality disorder, turn to addiction faster and easier than other people and such individuals are more affected by addiction such as work addiction.

The employees in Management and Planning Organization of Hamedan suffer very high mental tension due to high workload and also a great responsibility for drawing the urban landscape in order to achieve sustainable development and this causes the individuals to try and work constantly so that the possibility of physical and mental harm is very high for such people. Therefore, any lack of attention to issues such as work addiction can have negative effects on individual and organizational performance and efficiency and ultimately society which in the meantime, it is necessary to address the personality aspects of the employees and their identify, especially during recruitment and adjustment of individual personality with the responsibility assigned to him/her. On the other hand, work addiction can have different effects on the physical and psychological health of the individuals, their families and their colleagues. The most common consequences of work addiction is related to high levels of job stress and work-family conflict; although, the following items could be also considered: increase in healththreatening symptoms (physical and psychological), job erosion, creating problems and difficulties in team work, resignation and avoidance of interactions and family relationships, trouble communicating with others, low satisfaction with life, loss of enjoyment of leisure, etc. (Piotrowski \& Vodanovich, 2008). Now, according to the above descriptions and theories, the question is whether or not there is a significant relationship between personality dimensions of employees and work addiction in the Management and Planning Organization of Hamedan.

\section{Concepts and Theories}

\section{Definition of personality}

Realization school has considered personality in the physical and psychological concept and knows any developments in it related to changes in the individual's body and mind. In other words, personality refers to "bio-psychological structure of individual or total of internal and individual factors as well as social factors" (Izadi, 1972).

\section{Personality and its dimensions}

As the decisive factor affecting all human behaviors in personal and social life, personality can be problematic for the person and those around it due to maladaptive traits (Atkinson et al., 2016). Personality can be defined as specific profile of overt behavioral response patterns in normal life; a 
totality that is usually fixed and predictable (Izadi, 1972). Today, there are different views of personality in psychology such as psychoanalytical views, coverage views, phenomenological views, information processing views and interactive views.

One of the approaches with relative acceptability among the experts is factor theory of personality. The main question in this theory is whether there are some indicators for personality which put desired characteristics of society and individuals in the subset of the elements or index in describing the personality. During the historical development of this approach, the infrastructure factors of personality have been called trait or personality dimensions. Five-factor theory of personality that is also known as Big Five was introduced by Costa and McCrae in the late 80s and then it was evaluated in the early 90s. The foundation of this theory was primarily Eysenck's works. Mathews and Deary (1996) suggest that this theory has logical and theological bases in some ways and it is statistical infrastructure from some aspects. Five main factors or personality dimensions include: extroversion, altruism, flexibility, incompatibility, responsibility.

\section{Extroversion}

Extroversion refers to the part of the traits and it is the degree to which a person is energetic, sociable, courageous, active, thrill-seeking, enthusiastic, and self-confident with positive emotions. Extroverted people tend to be sociable, emotional and intimate and they treat better with different people. While working, the extroverted people have positive spirits and moods, they feel more satisfaction about their job and they generally feel better about the organization and its environment (Goldberg, 2001).

\section{Flexibility}

Flexibility is related to the tendency of individuals to be matched with others. Flexible individuals are reliable, honest, altruist, compassionate with the characteristics of selflessness, follower, humble and good hearted. Flexible people are usually leaders of teams. Also, they are suitable for teaching and psychology and counseling affairs, social works and activities. These people try to create adjustment and deal easily with people and they usually avoid controversial and disputable discussions (Schultz \& Schultz, 2016).

\section{Responsibility}

This dimension is the measure of reliability. Responsible person with high conscientious is competent, orderly, conscientious, purposeful, punctual and reliable with personal discipline. Responsibility is considered to be useful and important in many organizational contexts and it is an accurate predictor of performance in many jobs because the desire of such individuals to achieve success is greater.

\section{Incompatibility}

This dimension is related to the person's ability to tolerate stress. Incompatible people have low emotional stability. These people are worried, nervous, frustrated, stressful, shy, vulnerable and hasty. Incompatible people have usually negative moods in their workplace and negative attitudes towards their works. In group decision-making, these people may have sobering influence which is done through expression of taken negative aspects (Schultz \& Schultz, 2016).

\section{Altruism}

Last dimension indicates the amount of interest of people in novelty and new experiences. People with this feature have power of imagination, open emotions and ideas; they are pragmatist and curiosity about the ideas of others. Such individuals can be useful for jobs in which large variations occur or require innovation or considerable risk. For example, entrepreneurs, architects, agents of change in 
organizations, artists and theorist scientists are generally in the high-level in terms of this feature (Schultz \& Schultz, 2016).

\section{Work addiction}

Work addiction is an addiction that may be enjoyable but frustrating and problematic, so that even some people consider it as a disease. They assume that they are the only ones who can do this particular work; they are addicted to work because of indulge in work. Although most cases of work addiction are associated in a high-paying job, it may be true about those who participate in sports, music, and art and so on extremely. This term is often mistakenly used on the personality of energetic and hardworking individuals who consider significant amount of time to work in addition to having a good relationship with colleagues, enjoying the non- financial gain activities, adequate rest and proper participation in family and society. These people are normal who only difference from the others is proper planning in personal and professional life. A person with work addiction behaves in a way that all efforts is detrimental for itself, family and social life outside of work. This leads to frustration, lack of good relationship with colleagues or lack of time and energy for the family life, friends, hobbies and other activities (Burke et al., 2006).

Different definitions about the term of work addiction can be found in the literature. Reviewing various literature, these definitions can be compared from four approaches (Douglas \& Robyn, 2006).

- Definitions which have been expressed in terms of behavioral dimension (Scottl et al., 1997) or attitudinal dimension (Spence \& Robbins, 1992).

- Definitions which have been described as uncontrollable addiction (Oates, 1971).

- Definitions which have been expressed with positive view or negative view (Oates, 1971).

- Definitions known as various types with different backgrounds (McMillan et al., 2003; Scottl et al., 1997; Spence \& Robbins, 1992).

- Oates (1971) knows work addiction as a kind of acclimatization to something. According to him, addicted to work are people who need extremely to work so that there may be a serious risk to their health, personal happiness, interpersonal relationships and social roles and tasks; because they have an unreasonable obligation to too much work and devote much more time to work activities intrinsically and arbitrarily.

- Spence and Robbins (1992) offered the first academic and practical definition for the term of work addiction. According to them, work addiction has originated from a series of attitudes and perceptions of individuals. They consider the addict to work as a person who is involved in the work to a high level, and has high compulsive emotions or extraordinary inner passion to work and takes little pleasure from his/her work.

\section{Personality aspects and its effect on work addiction}

Rotter (Themanson et al., 2008) is rooted in social learning theory. In fact, locus of control refers to the individual belief in its ability to control life events. The term of locus of control is often used with the word of self-esteem. However, the two terms are not synonymous. Self-esteem refers to the ability to do something appropriately and effectively, but the locus of control focuses on the concept of control. People who have an internal locus of control can affect the environment and its events. Such people are called intro-controlled individuals who accept responsibility for failures and frustrations themselves and avoid leaving it to chance and they believe that the results are consequence of their own behavior and personal endeavor. But some people believe that the results are not associated with their behavior and their performance is mainly affected by environment and their fortune has made such a destiny for them. For such people, locus of control is external. Research shows that people with internal locus of control have more work motivation, greater job satisfaction, higher income and greater efficiency. Also, 
many studies show that external locus of control has an inverse relationship with job satisfaction and positive relationship with stress (McMillan et al., 2003; Themanson et al., 2008). Research shows that people with internal locus of control have greater work commitment (Chen \& Wang, 2006). Hence, those who have internal locus of control are associated with their work and spend more obsession in doing things.

Some psychiatrists believe that such individuals replace all their natural needs with satisfaction from the work and attention resulted from efficiency and they are incapable of creating human relationships based on healthy emotions. There are many common features among different types of addictive behaviors in these individuals. First of all, these people become obsessive about the particular object, activity or material; they think about it constantly and are seeking to achieve it which this behavior often hurts their job performance or interpersonal relationships. This person is engaged in this activity compulsorily and he /she cannot stop it; in other words, he/she has no control over this behavior. Some withdrawal symptoms including irritability, high voracity for the desired activity and restlessness appear followed by leaving aside the desired activity, material and behavior. The person often denies the problems resulted from engaging in this activity. People with normal or addiction-like behaviors have usually low self-esteem and if they have no control over their environment, they will get anxious.

\section{Narcissism}

Ellis was the first person who used the term of "Narcissus" in psychology and then Freud used the "Narcissistic" word in two fields of normal and abnormal (pathological) in his work. All people are somewhat narcissist and normal narcissism is not far from reality (Brown, 1997). Narcissism refers to extreme self-love, pride, conceit, egotism, lack of empathy with others and self-centered (Jørstad, 1996). Ideally, normal narcissism makes the individuals to have a positive impact on the working consequences, work environment and ultimately feelings of others. Abnormal narcissistic personality sees itself as a special entity. About fifteen percent of people have abnormal narcissistic personality of where men constitute about sixty percent (Vazire et al., 2008). Some features of this type of narcissism include megalomania, confusion, fear, unrealistic and fictitious identity and a sense of emptiness and emptiness, insatiable need for the superiority, high sensitivity and anger, lack of empathy, failure to comply with ethical principles, irrationality and inflexibility, arrogance, vulnerability and blaming others, insatiable desire to be loved, show off and acquisition of excessive power, the use of expensive and stylish clothes with famous brands (Dimaggio et al., 2002; Jørstad; 1996; Vazire et al., 2008). These people have an insatiable desire to be loved, show themselves to the world and gain power (Boyett, 2006). Prosperous narcissist people can show a pleasant face to attract people (McCoy, 2006) and they employ their skills and abilities in order to influence on others and threaten them. Narcissist people do not follow ethical principles and they have impossible demands from others and when they do not receive a response, they suspect that others deprive them of the right of life. Such individuals have inflexible behavior and thinking and instead of logic and acceptable rationality, they make a decision according to their wishes. A narcissist person has the Nihilism delusion, mistrust and suspicion towards the most loyal people and he makes an enemy for itself in its own mind even where there is no enemy. He /she trusts others hardly and seeks to control. Such individual is cold hearted and merciless to win and tends to create a plan to change the world. So, it can be seen that narcissism is like a doubleedged sword that having its too much or too low value causes an imbalance in the person. The same characteristics which can be used in a narcissistic person can be also destructive, such as the pursuit of power which can be turned to compete and be pursued at any cost. Establishing relationships can also lead to the exploitation of others (Dimaggio et al., 2002). It should be noted that exaggerated assessments of the abilities of narcissist individuals by themselves is not associated with their high capacity. Numerous studies show that dark edge of narcissist leaders' personality is seen more in the charismatic leaders (Khoo \& Burch, 2008). Also, some studies show that there is a relationship between

confidence and narcissism. So, senior managers of the organizations are advised to avoid the narcissism; because narcissism is very common among senior managers and it is suggested that 
organizational leaders adapt themselves with reality instead of ideals because of the dangerous nature of this phenomenon. Therefore, many senior managers with narcissism feel that they are immortal and have little need to the successful planning which is very dangerous for the organization (Amenic \& Craij, 2008). Many empirical evidences suggest that narcissism is associated with aggression. The relationship between narcissism and aggression is explained by aggressive selfishness theory; that is, it is assumed that attack or aggression is means to define own desired look against others and assassination of personality of opposite side (Martinez et al., 2008). Six dimensions of denial, justification, megalomania, attributive selfishness, eligibility and legitimacy, anxiety and worry have been considered as narcissistic personality dimensions (Stoeber et al., 2008) including:

1. Denial: narcissistic personality often denies the difference between ideal self and actual self. Denial leads to escape from accepting responsibility for errors.

2. Justification: find the reason for unacceptable behaviors in order to present them in an acceptable form so that tasks, policies and decisions seem reasonable.

3. Megalomania: narcissist person boasts about itself abilities and overestimates own knowledge, achievements and skills.

4. Attributive selfishness: person attributes desired outcomes, successes and positive results to own internal factors and alternatively, he attributes undesirable outcomes, failures and negative consequences to external factors.

5. Eligibility: the person knows own right to exploit others and he /she does not empathize with others.

6. Anxiety: person suffers from depression and feeling of worthlessness and he / she has a pressing need for stability and certainty.

One of the scenes of development of narcissism is organizations. Narcissist people can show their skills and capabilities on the job. Narcissist people try to boast their abilities and successful decisions on the job; so, they spend significant amount of time to work. Also, some theorists in the field of addiction believe that addiction and enthusiasm to the work is caused by person infatuation to the work. Freud used this phenomenon in two fields of normal and abnormal (pathological). All people are somewhat narcissist and normal narcissism is not far from reality (Brown, 1997).

Ideally, normal narcissism makes the individuals to have a positive impact on the working consequences, work environment and ultimately feelings of others. Abnormal narcissistic personality sees itself as a special entity. About fifteen percent of people have abnormal narcissistic personality and men constitute about sixty percent (Woonnerberg, 2007).

\section{Self-confidence}

One of the important psychological factors affecting the cognitive health of individuals during adolescence is self-confidence. Self-confidence plays a very important role in modulating selfregulation and successful completion of challenging tasks (Themanson et al., 2008) and it is considered as the source of an individual belief in his/her ability to handle difficult tasks (Stoeber et al., 2008). Special self-confidence referring to Bandura conceptualization is the belief of successful completion of technical tasks. Bandura believes that self-esteem implies a specific task in the given situation and it is a context-dependent feature. On the contrary, general self-confidence refers to the individual belief about successful completion of tasks.

Evaluation of individual beliefs often occurs when people are faced with new and unpredictable works. So, self-confidence is the product of multiple sources. The key sources of the information include verbal persuasion such as performance feedback and physiological factors such as changes in expression of feelings like anxiety, fear and positive forecasts (optimistic). Bandura considers four sources effective in self-confidence. In his opinion, previous experience is the most powerful source of self-confidence. 
How the behavior of others in similar activities is effective in creating a sense of self-confidence. Similarly, encouraging the individuals has an effect on doing things efficiently. Physical and psychological factors also play a major role in self-confidence.

There is an effective relationship between self-confidence and reduced anxiety, addiction control, tolerance for pain, recovery. The relationship between self-confidence and success or failure is cyclical; this means that people with high self-confidence achieve more success and people with low selfconfidence face with more failures. Four types of self-confidence have been presented in the field of entrepreneurship:

- Identity-opportunity self-confidence: it is a kind of self-confidence that recognizes market opportunities and new products better than others.

- Relational self-confidence: it is a kind of self-confidence which has the ability to build a relationship with potential investors and individuals who are connected to the capital sources and they can take advantage of opportunities better than others after identifying opportunities.

- Managerial self-confidence: it is a kind of self-confidence that individuals have in relation to the managerial ability, especially in the field of economy and financial management of their firm.

- Stable self-confidence: it is a kind of self-confidence which has ability to do things with high efficiency under the conditions of stress, conflict and modification continuously (Barbosa et al., 2007).

The researchers concluded that the academic self-confidence helps to predict academic ranks and performance of individuals in academic environments. The study also showed that of the four selfconfidence sources mentioned by Bandura, previous experience has a greater impact on increasing academic self-confidence than the rest of the sources (Girasoli \& Hannafin, 2008). Of course, it should be noted that self-confidence does not necessarily lead to increased addiction; but in various situations, the individuals with high self-confidence have more obsession to work and they are largely associated with their work.

\section{Research methodology}

This study is descriptive-correlation and it is also an applied research in terms of its nature. The statistical population includes all employees in Management and Planning Organization in Hamedan who work in 2016 and their total number is 74 subjects. In this study, the statistical sample of employees was estimated up to 62 individuals using Morgan and Krejcie tables with simple random method. The measuring tools in the present study include:

\subsection{Personality Dimensions Inventory}

The measuring tool of independent variable is NEO 50-item revised personality dimensions inventory which is one of the personality tests made based on factors analysis and it was introduced by Costa and McCrae (1992) as the latest tool in the field of personality. This questionnaire has five main personality factors that include: incompatibility, extraversion, flexibility, altruism, responsibility and conscientiousness. The revised form (short form) of this questionnaire has not been validated in Iran, but studies by Costa and McCrae (1992) showed that the correlation of short form components with the long form ones is 0.77 to 0.92 . Also, the internal consistency of its subscales has been satisfies ranged from 0.68 to 0.86 . Scoring method of the questions is in the form of five-option Likert in this questionnaire. In this study, the reliability with Cronbach's alpha coefficient for personality dimensions inventory was estimated 0.76 and its dimensions including incompatibility, extraversion, altruism, flexibility and responsibility and conscientiousness were obtained $0.75,0.88,0.73,0.78$ and 0.77 , respectively. 


\subsection{Work Addiction Inventory}

In this study, the addiction questionnaire originally developed by Spence and Robbins (1992) was used with 20 five-option questions. This questionnaire has three dimensions (job involvement, enjoyment of work and inner desire to work) where each of them has been marked with a number of questions. In the research accomplished in Iran, Cronbach's alpha coefficient of this questionnaire was obtained 0.756. In this study, the reliability with Cronbach's alpha coefficient for the work addiction inventory was 0.78 and its dimensions such as job involvement, enjoyment of work and inner desire to work were obtained $0.72,0.75$ and 0.72 , respectively.

\section{Findings}

\subsection{Research hypotheses testing}

Five hypotheses have been examined and the results of correlation test have been presented in Table 1 as follows,

Table 1

Results of correlation test

\begin{tabular}{cccccc}
\hline Hypothesis & Independent variable & $\begin{array}{c}\text { Dependent } \\
\text { variable }\end{array}$ & $\begin{array}{c}\text { Correlation } \\
\text { coefficient }\end{array}$ & Significance level & Conclusion \\
\hline 1 & Incompatibility & Work addiction & 0.586 & 0.001 & $\mathrm{H}_{0}$ Rejects \\
2 & Extraversion & Work addiction & -0.361 & 0.004 & $\mathrm{H}_{0}$ Rejects \\
3 & Flexibility & Work addiction & -0.376 & 0.003 & $\mathrm{H}_{0}$ Rejects \\
4 & Altruism & Work addiction & 0.773 & 0.001 & $\mathrm{H}_{0}$ Rejects \\
5 & Responsibility & Work addiction & -0.284 & 0.025 & $\mathrm{H}_{0}$ Rejects \\
\hline
\end{tabular}

For all hypotheses, the significance level obtained from Pearson test is less than 0.05 which indicates that there is a significant relationship between two independent and dependent variables with $95 \%$ confidence level in all hypotheses. Also, positive correlation coefficient in the first hypothesis suggests that the increased level of incompatibility of individuals in working environment increases their work addiction.

Negative correlation coefficient in the second hypothesis suggests that the increased level of extraversion of individuals in working environment reduces their work addiction. Also, negative correlation coefficient in third hypothesis suggests that the increased level of flexibility of individuals in working environment reduces their work addiction. Moreover, positive correlation coefficient in fourth hypothesis suggests that the increased level of altruism of individuals in working environment increases their work addiction. Finally, negative correlation coefficient in fifth hypothesis suggests that the increased level of responsibility of individuals in working environment reduces their work addiction.

\subsection{Prioritizing the effect of employee's personality dimensions on work addiction}

Multiple Regression is used to confirm the prioritization of the effect of employee's personality dimensions on work addiction. In order to perform this test, it is necessary to implement the assumptions of regression analysis to achieve reliable results.

1. Assumption of correlation between criterion variable and independent variables (this assumption was reviewed and approved in first to fifth hypotheses)

2. Assumption of model explanation: in this case, it must be determined whether the independent variables can explain the criterion variable (the average effect of independent variables on the criterion variable). 
3. Assumption of investigation into the linear relationship between independent variables and criteria in which ANOVA is used.

Table 2 deals with the explanation of the regression model used in prioritizing the effect of employees' personality dimensions on the work addiction.

Table 2

Explanation of the regression model

\begin{tabular}{cccc}
\hline $\mathrm{R}$ & $\mathrm{R}$-squared & Adjusted R -squared & Durbin-Watson \\
\hline 0.833 & 0.694 & 0.666 & 1.833 \\
\hline
\end{tabular}

It is observed that adjusted R-squared is equal to 0.666 and about $67 \%$ change in work addiction variable is caused by changes in employees' personality dimensions, which means independent variables could approximately describe $67 \%$ of the changes in dependent variable. Also, because the value of Durbin-Watson is from 1.5 to 2.5 , the assumption of independence between the errors will be accepted. Table 3 examines the linear relationship between the criterion variable and predictor variable using ANOVA.

Table 3

Investigation into the linear relationship between predictor and criterion variables

\begin{tabular}{cccccc}
\hline Model & Sum of squares & df & Average of squares & F statistic & Sig \\
\hline Regression & 25.685 & 5 & 5.137 & 25.352 & 0.001 \\
Remaining & 11.347 & 56 & 0.203 & - & - \\
\hline Total & 37.032 & 61 & - & - & - \\
\hline
\end{tabular}

Obviously, the significance level is less than 0.50 , so the null hypothesis based on lack of linear relationship between predictor and the criterion variables will be rejected. Therefore, the assumption of linear relationship between predictor and criterion variables is confirmed according to this table. Since all three conditions of the use of multivariate regression test were taken into consideration, it should be presented a function by which prediction value of the predictor variable can be shown in the direction of criterion variable. In this regard, Table 4 shows regression coefficients.

Table 4

Regression coefficients

\begin{tabular}{|c|c|c|c|c|c|}
\hline & \multicolumn{2}{|c|}{$\begin{array}{l}\text { Non-standardized } \\
\text { coefficients }\end{array}$} & \multirow{2}{*}{$\begin{array}{c}\text { Standardized } \\
\text { coefficients } \\
\text { Beta } \\
\end{array}$} & \multirow[t]{2}{*}{ t statistics } & \multirow[t]{2}{*}{ Significance level } \\
\hline & B & Standard error & & & \\
\hline Constant & 0.378 & 0.525 & - & 0.721 & 0.474 \\
\hline Incompatibility & 0.202 & 0.127 & 0.181 & 1.524 & 0.119 \\
\hline Extraversion & -0.229 & 0.194 & -0.278 & -1.181 & 0.243 \\
\hline Flexibility & 0.845 & 0.114 & 0.777 & 7.385 & 0.001 \\
\hline Altruism & -0.379 & 0.163 & -0.535 & -2.321 & 0.024 \\
\hline Responsibility & -0.262 & 0.171 & -0.386 & -1.53 & 0.132 \\
\hline
\end{tabular}

According to Table 4, it can be said that the significance level of constant level test is more than 0.5; therefore, the assumption $\alpha=0$ is not rejected and the constant value does not affect the criterion variable, so that it cannot participate in non-standard coefficients equation. Also, the significance levels of altruism and flexibility coefficient test are less than 0.5 , so they are appropriate to enter the standard coefficients equation or in other words, they can affect the criterion variable. While significance levels of incompatibility, extraversion, responsibility and conscientiousness are more than 0.5 and they cannot enter the equation. Now given the above explanations, standard and non-standard coefficients function is as follows: 
Standard equation

Work addiction $=(0.777)($ Altruism $)-(0.535)($ Flexibility $)+\varepsilon$

Using the above formula, we can conclude that dimensions of altruism and flexibility can predict the value of work addiction due to the constant external factors. While the dimensions of incompatibility, extraversion, conscientiousness and responsibility cannot be used to predict the work addiction variable. According to $\beta$ coefficient in altruism dimension, it can be also said that altruism dimension has greatest impact on work addiction in the Management and Planning Organization of Hamedan and after that, flexibility dimension is more effective.

\section{Discussion and Conclusion}

According to the first hypothesis which examines the relationship between incompatibility and work addiction of employees in the Management and Planning Organization of Hamadan, it can be said that there is a significant relationship between incompatibility and work addiction variables. In other words, higher level of incompatibility characteristics among employees will lead to an increase in symptoms of work addiction at their jobs. In this regard, the results from researches by Gholipour et al. (2010), Ahmadi et al. (2010), Mahmoudian (2014), Nargesian et al. (2012), Pour et al. (2013), Mohkamkar and Damghani (2013), Mahmoudi (2014), Scottl et al. (2007), Hamermesh \& Slemrod (2008), Petroski and Wendavch (2008), Burke and colleagues (2009), Synr and Harpz (2010), Golzari et al. (2014) and Pour et al. (2013) are consistent with obtained results. Because they showed that work addiction may be affected by the personality dimensions such as incompatibility and the higher level of incompatibility is related to increased work addiction and job burnout that is one of the symptoms of excessive and unplanned work.

Therefore, comparison of the previous researches and the first hypothesis of the present study concludes that along with the emergence of incompatibility characteristics such as emotional distress, social phobia, depression, anxiety, hostility and hatred more and more in the entity of individuals, we will see less happiness and satisfaction, because the characteristics of such individuals are quite contrary to the happiness and they are less happy; because they are more prepared to accept the psychological distress and their fragile emotions prevent their compatibility with the surrounding environment and consequently isolation increases in them and we will not see the defined subscales of satisfaction with work in such individuals due to autism. In this regard, we can go further and say that individuals who gain higher scores for this type of personality have antisocial personality and emotional disorders and they cannot communicate with others and control their emotions properly and this will certainly contribute to incidence of symptoms of work addiction and job burnout. Because incompatible individuals are not able to create the healthy and constructive relationships in social environments such as work environment and such individuals turn to isolationism and isolation in the working environment. They try to keep themselves busy by excessive and unplanned working for not having useful relations and interactions with others in workplace which can addict them to the working extremely. Compared with others, such individuals have too much anxiety and so they experience stress and distress while doing assigned duties in the organization and they believe that they can reduce their anxiety and worry by working too much and therefore, they may do works many times due to the high anxiety caused by their personality characteristics and this makes them addicted to work continuously. According to the second hypothesis which examines the relationship between extraversion and work addiction of employees in the Management and Planning Organization of Hamadan, it can be said that there is a significant relationship between extraversion and work addiction variables. In other words, higher level of extraversion characteristics among employees will reduce the symptoms of work addiction at their jobs. In this regard, the results from researches by Gholipour and colleagues (2010), Ahmadi et al. (2010), Mahmoudian (2011), Nargesian and colleagues (2012), Pour et al. (2013) and colleagues (2013), Mohkamkar Damghani (2013), Mahmoudi (2014), Scottl et al. (2007), Hamermesh 
and Slemrod (2008), Golzari et al. (2014) and Pour et al. (2013) are consistent with obtained results. Because they showed that work addiction may be affected by the personality dimensions such as extraversion and the higher level of extraversion is related to reduced work addiction and job burnout which are the symptoms of excessive and unplanned working. Therefore, comparison of the previous researches and the second hypothesis of the present study concludes that along with the emergence of extraversion characteristics such as desire to connect with others, interest in being in large groups and gatherings, being bold, being active, being talkative and so on more and more in the individuals, we will see an increase in their life expectancy. Because the extraversion personality has a direct and positive relationship with a sense of job satisfaction and lack of job-related depression which is one of the symptoms of work addiction. Extroverts are happier, more energetic and more optimistic that all mentioned characteristics are related to the lively people. Such individuals look at the world around them with another approach. Extroverted people are more sociable, more decisive and adaptation, social orientation, trust and good-heartedness are of other characteristics of these individuals. So, it can be concluded that job satisfaction and hope for occupational future have been tied with extraversion personality and they are some characteristics of these individuals. Extroverted people have a positive attitude to their environment which can be also true for employees; because the higher level of extraversion in the entity of employees leads to more relationship with their profession because of their positive view which forms their job satisfaction and happiness.

According to the third hypothesis which examines the relationship between flexibility and work addiction of employees in the Management and Planning Organization of Hamadan, it can be said that there is a significant relationship between flexibility and work addiction variables. In other words, higher level of flexibility characteristics among employees will reduce the symptoms of work addiction at their jobs. In this regard, the results from researches by Gholipour et al. (2010), Ahmadi et al. (2010), Mahmoudian (2014), Nargesian et al. (2012), Pour et al. (2013), Mohkamkar Damghani (2013), Mahmoudian (2014), Scottl et al. (2007), Hamermesh \& Slemrod (2008), Petroski and Wendavch (2008), Golzari et al. (2014) and Pour et al. (2013) are consistent with obtained results. Because they showed that work addiction may be affected by the personality dimensions such as flexibility and the higher level of flexibility is related to reduced work addiction and job burnout which are the symptoms of excessive and unplanned working. Therefore, comparison of the previous researches and the third hypothesis of the present study concludes that along with the emergence of flexibility characteristics such as having a sense of liking beauty of surrounding environment, paying attention to the inner feelings, seeking diversity, intellectual curiosity, independence in judging and so on more and more in individuals, we will see increased job satisfaction in them. Flexible individuals have more desire to accept new beliefs and unconventional values by others because of the nature of their entity which can strengthen their relationship with others and help them to adapt to the changes in the job appropriately. Basically, one of the causes of work addiction is the ongoing transformations in the working environment that flexible individuals cope properly with the conditions and adapt themselves to created conditions. Because the individuals with high level of work addiction always adapt themselves to their working conditions and become dependent on it and so any shift is unboreable and hard for them and they cannot accept it. Therefore, flexible individuals adapt to the changes easily because of lack of addiction to working conditions and accept them.

According to the fourth hypothesis which examines the relationship between altruism and work addiction of employees in the Management and Planning Organization of Hamadan, it can be said that there is a significant relationship between altruism and work addiction variables. In other words, higher level of altruism characteristics among employees will increase the symptoms of work addiction at their jobs. In this regard, the results from researches by Gholipour et al. (2010), Ahmadi et al. (2010), Mahmoudian (2011), Nargesian et al. (2012), Pour et al. (2013), Mohkamkar Damghani (2013), Mahmoudian (2014), Scottl et al. (2007), Hamermesh and Slemrod (2008), Petroski and Wendavch (2008), Burke and colleagues (2009), Synr and Harpz (2010), Golzari et al. (2014) and Pour et al. (2013) are consistent with obtained results. Because they showed that work addiction may be affected 
by the personality dimensions such as altruism and the higher level of altruism is related to the increase in work addiction and job burnout which are the symptoms of excessive and unplanned working. Therefore, comparison of the previous researches and the fourth hypothesis of the present study concludes that along with the emergence of altruism characteristics such as more attention to the demands of others, having a sense of solidarity with others, lack of attention to their own demands in relationships, more attention to the opposite side and so on more and more in individuals, we will see increased job burnout and work addiction. Because people with a pleasant personality are more willing to help others in workplace because of a sense of altruism and this increases the level of their duties and work addiction is one of the signs that may occur in the person with increasing workload. In addition to take over their own duties extremely, addicts to work undertake the duties and responsibilities of others because of their extreme humanitarian feelings and this can increase their work hours due to the increased level of work responsibility of others and gradually, the person will fall into the trap of work addiction.

According to the fifth hypothesis which examines the relationship between responsibility and work addiction of employees in the Management and Planning Organization of Hamadan, it can be said that there is a significant relationship between responsibility and work addiction variables. In other words, higher level of responsibility characteristics among employees will reduce the symptoms of work addiction at their jobs. In this regard, the results from researches by Gholipour et al. (2010), Ahmadi et al. (2010), Mahmoudian (2011), Nargesian et al. (2012), Pour et al. (2013), Mohkamkar Damghani (2013), Mahmoudi (2014), Scottl et al. (2007), Hamermesh \& Slemrod (2008), Petroski and Wendavch (2008), Burke and colleagues (2009), Synr and Harpz (2010), Golzari et al. (2014) and Pour et al. (2013) are consistent with obtained results. Because they showed that work addiction may be affected by the personality dimensions such as responsibility and the higher level of responsibility is related to reduced work addiction and job burnout which are the symptoms of excessive and unplanned working.

Therefore, comparison of the previous researches and the fifth hypothesis of the present study concludes that along with the emergence of responsibility characteristics such as thinking before any action, lack of procrastination, and procrastination in work, compliance with laws, regulations and norms, organizing tasks and prioritizing the factors and so on more and more in individuals, we will see reduced work addiction in them. Responsibility can have benefits and positive effects on people's lives and makes them lawful and committed. Responsibility and conscientiousness also cause the person not to delay things and perform job duties at the appointed time that in this case, it no longer will be needed to extreme and unplanned work. Responsible individuals benefit from the careful organization and planning the works and such regular structure does not allow the person is affected to work out too or the same work addiction. But responsibility can also have a degree and level and it is possible that person always see itself within the framework of laws and regulations due to extreme responsibility; so, they will feel less calmness. In the higher degrees, they will become obsessive, sensitive, cautious individuals with more addiction to work.

\section{References}

Ahmadi, P., Tahmasebi, R., Babashahi, O., \& Fattahizadeh, M. (2010). The role of personality factors in the formation of workaholism (Case Study: Faculty of Tehran University). Research Management, 3(2), 67-46. (In Persian)

Amenic, J.H. \& Craij, R.J. (2008). Leading in language: What the CEO should and should not say. Strategic Direction, 4(2), 24-25.

Atkinson, J. O. (2016). Aspergers, Inside Looking Out. International Journal of School and Cognitive Psychology, 2016.

Barbosa, S.D., Gerhardt, M.W., \& Kicku, J.R. (2007). The role of cognitive style and risk preference on entrepreneurial self-Efficacy and entrepreneurial intentions. Journal of Leadership and Organizational Studies, 13(4), 86-104. 
Boyett, J. H. (2006). Surviving the destructive narcissistic leader. Atlanta, GA: Boyett \& Associates.

Brown, A. (1997). Narcissism, identity and legitimacy. Academy of Management Review, 22(3), 643686

Burke, K., Burgess, Z., \& Fullon, B. (2006). Workholism among Australian female management and professionals. Equal Opportunities International, 25(3), 200-210.

Carver, C. S., \& Scheier, M. F. (2013). Goals and emotion. Guilford handbook of cognition and emotion, 176-194.

Chen, J., \& Wang, L. (2006). Locus of control and the three components of commitment to change. Personality and Individual Differences, 42, 503-512.

Costa, P. T., \& McCrae, R. R. (1992). Four ways five factors are basic. Personality and Individual Differences, 13(6), 653-665.

Dimaggio, G. Semerari, A., Falcone, M., Nicolo, G., Carcione, A., \& Proccaci, M. (2002). Metacognition, states of mind, cognitive biases, and interpersonal cycles: Proposal for an integrated narcissism model. Journal of Psychotherapy integration, 12(4), 421-451.

Douglas, E. J., \& Morris, R. J. (2006). Workaholic, or just hard worker?. Career Development International, 11(5), 394-417.

Gholipour, A., Nargesian, A., \& Tahmasby, R. (2010). Workaholism: New challenges for human resource management organizations. Knowledge Management, 81, 91-110.

Girasoli, A. J., \& Hannafin, R. D. (2008). Using asynchronous AV communication tools to increase academic self-efficacy. Computers \& Education, 51(4), 1676-1682.

Goldberg, L. R. (2001). The comparative validity of adult personality inventories: Applications of a consumer-testing framework. Handbook of adult personality inventories. New York: Plenum.

Golzari, A. A., Montazeri, M., \& Paktinat, E. (2014). Relationship between Work holism and Organizational Citizenship Behavior among Schools Employees in Sirjan-Iran. Journal of American Science, 9(2).

Hamermesh, D., \& Slemrod, J. (2008). The economics of workaholism: we should not have worked on this paper. Journal of Economic Analysis and Policy, 8(1), 124-132.

Izadi, S. (1972). Personality psychology from the perspective of schools. Tehran: Dehkhoda.

Jørstad, J. (1996). Narcissism and leadership: Some differences in male and female leaders. Leadership \& Organization Development Journal, 17(6), 17-23.

Khayfallahi, A.A., Nargesian, A., \& Babashahi, J. (2012). Study the relationship between workaholism and organizational citizenship behavior. Research Management, 4(7), 1-10. (In Persian).

Khoo, H. S., \& Burch, G. S. J. (2008). The 'dark side'of leadership personality and transformational leadership: An exploratory study. personality and individual differences, 44(1), 86-97.

Mahmoud, M. (2014). The relationship between irrational beliefs and personality with work addiction in Kermanshah high-school administrators. Master thesis, Faculty of Economics and Social Sciences, Tehran, Razi University.

Mahmoudian, Z. (2014). The relationship between workaholism and analysis of occupational burnout of physical education teachers in Kermanshah. Master thesis, Faculty of Literature and Human Sciences, Hamedan: Bu Ali Sina University.

Martinez, M. A., Zeichner, A., Reidy, D. E., \& Miller, J. D. (2008). Narcissism and displaced aggression: Effects of positive, negative, and delayed feedback. Personality and Individual Differences, 44(1), 140-149.

Matthews, G., Deary, I. J., \& Whiteman, M. C. (2003). Personality traits. Cambridge University Press.

McCoy, D. (2006). The Manipulative Man: Identify His Behavior, Counter the Abuse, Regain Control. Adams Media.

McCormick, J., \& Barnett, K. (2008). A multilevel investigation of relationships between Australian teachers' career stages and locus of control. Journal of educational administration, 46(1), 8-24.

McMillan, L. H., O Driscoll, M. P., \& Burke, R. J. (2003). Workaholism: A review of theory, research, and future directions. International review of industrial and organizational psychology, 18, 167-190. 
Mohkamkar Damghani, J. (2013). The relationship between personality and addiction agencies working in the city of Damghan. Master's thesis, Faculty of Human Sciences, Semnan, Iran: Islamic Azad University.

Narimani, M. \& Khanbabazadeh, M. (2007). To assess personality traits and job satisfaction Ardabil universities. MA thesis, Ardabil: Ardabil Azad University.

Nargesian, A., Babashahi, J. \& Afkhami, M. (2012). The consequence of a positive and constructive approach to workaholism, articles, conferences Iran. Tehran: Human Resource Development Conference Center, productivity and human resources.

Piotrowski, C., \& Vodanovich, S. J. (2008). The workaholism syndrome: an emerging issue in the psychological literature. Journal of Instructional Psychology, 35(1), 103-106.

Pervin, L. A., \& John, O. P. (1999). Handbook of personality: Theory and research. Elsevier.

Pour, S. H., Hasanvand, B., \& Khaledian, M. (2013). The relationship of psychological hardiness with work holism. International Letters of Social and Humanistic Sciences, (05), 1-9.

Scottl, K. S., Moore, K. S., \& Miceli, M. P. (1997). An exploration of the meaning and consequences of workaholism. Human Relations, 50(3), 287-314.

Schultz, D. P., \& Schultz, S. E. (2016). Theories of personality. Cengage Learning.

Spence, J. T., \& Robbins, A. S. (1992). Workaholism: Definition, measurement, and preliminary results. Journal of personality assessment, 58(1), 160-178.

Stoeber, J., Hutchfield, J., \& Wood, K. V. (2008). Perfectionism, self-efficacy, and aspiration level: Differential effects of perfectionistic striving and self-criticism after success and failure. personality and individual differences, 45(4), 323-327.

Themanson, J. R., Hillman, C. H., McAuley, E., Buck, S. M., Doerksen, S. E., Morris, K. S., \& Pontifex, M. B. (2008). Self-efficacy effects on neuroelectric and behavioral indices of action monitoring in older adults. Neurobiology of Aging, 29(7), 1111-1122.

Vazire, S., Naumann, L. P., Rentfrow, P. J., \& Gosling, S. D. (2008). Portrait of a narcissist: Manifestations of narcissism in physical appearance. Journal of Research in Personality, 42(6), 1439-1447.

Woonnerberg, D. (2007). The Nature of Narcissism within Organizational leadership. Dissertation presented in partial fulfilment of the requirement for the degree Doctor of Philosophy.

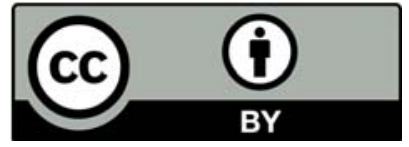

(C) 2016 by the authors; licensee Growing Science, Canada. This is an open access article distributed under the terms and conditions of the Creative Commons Attribution (CC-BY) license (http://creativecommons.org/licenses/by/4.0/). 